\title{
Virulent and attenuated lines of Leishmania major: DNA karyotypes and differences in metalloproteinase GP63
}

\author{
Jovana Sádlová ${ }^{1}$, Petr Volf ${ }^{1}$, Kathleen Victoir ${ }^{2}$, Jean-Claude Dujardin ${ }^{2}$ and Jan Votýpka ${ }^{1}$ \\ ${ }^{1}$ Department of Parasitology, Charles University, Viničná 7, 12844 Prague 2, Czech Republic; \\ ${ }^{2}$ Laboratory of Molecular Parasitology, Institute of Tropical Medicine "Prince Leopold”, 155 Nationalestraat, B-2000 Antwer- \\ pen, Belgium
}

Key words: Phlebotomus, sand flies, Leishmania major, virulence, leishmanolysin, LPG, proteolytical activity, genomic organisation, minichromosomes, LD1

\begin{abstract}
The Leishmania metalloproteinase GP63 has been reported to play important roles mainly in resistance of promastigotes to complement-mediated lysis and in interaction with macrophage receptors. On the other hand, its function in insect vectors is still unclear. We compared the structure and dosage of gp63 genes and the activity of GP63 in Leishmania major Yakimoff et Schokhor strains and lines differing in virulence for mice and ability to develop in sand flies. The results demonstrate considerable variability in amount and proteolytical activity of GP63 among L. major strains although genomic changes in the gp63 locus were not found. Attenuated LV561/AV line showed low amount and low enzymatic activity of GP63. Serial passages of attenuated parasites through either Phlebotomus duboscqi Neveu-Lemaire or through mice led to a recovery of GP63 proteolytical activity to the level present in virulent LV561/V line. Overexpression of GP63 was found in two L. major strains (L119, Neal) with defective lipophosphoglycan (LPG); both these strains were capable to cause mice infection but unable to survive and multiply in sand flies. Differences were found also in karyotypes and in amount of minichromosomes amplified in some lines of the LV561 strain. The results suggest that parasite virulence is not simply correlated with the activity of GP63; however, this enzyme plays a significant role in association with other surface molecules, especially LPG. Overexpression of GP63 can compensate LPG defect in the vertebrate host but in sand flies both molecules fulfil quite different functions and the defect in LPG is lethal for the parasite. On the other hand, linear minichromosomes of about $200 \mathrm{~kb}$ found in some lines of the LV561 strain are associated with development in vitro and in the vector but they are not essential for the infection of the vertebrate host.
\end{abstract}

Leishmania parasites encounter during their life cycle (i) the gut and mouthparts of the sand fly vector and (ii) macrophages of the vertebrate host. The surface molecules, particularly glycoprotein of $63 \mathrm{kDa}$ (GP63) and lipophosphoglycan (LPG), were found to be crucial for parasite survival in these two completely different environments. Both are GPI-anchored glycoconjugates constituting major components of a dense glycocalyx covering the entire surface of promastigotes.

Leishmanolysin GP63 is the major surface protease of Leishmania parasites. It is active in a neutral to alkaline $\mathrm{pH}$ range on a wide range of protein substrates (Etges et al. 1986, Bouvier et al. 1989). The glycoprotein is encoded by a family of tandemly linked genes which show marked heterogeneity among some Leishmania species (reviewed by Medina-Acosta et al. 1993). In L. major, there are seven gp63 genes and they exhibit stage-specific differences in their expression: five homologous tandemly repeated gp63 genes 1-5 are expressed in promastigotes only, a separated gene 6 is expressed in both promastigotes and amastigotes, while a gene 7 is expressed in stationary phase promastigotes and amastigotes (Voth et al. 1998). Recent genetic studies showed that GP63 has a role in binding to macrophages and in intracellular development of $L$. ama- zonensis (Chen et al. 2000) and in resistance to complement-mediated lysis in L. major (Joshi et al. 1998, 2002).

The importance of GP63 in the sand fly is indirectly supported by the fact that surface metalloproteinases similar to leishmanolysin GP63 were found in monoxenous insect trypanosomatids Crithidia fasciculata and Herpetomonas samuelpessoai (Etges 1992), but the function of GP63 in a vector is still unclear. The enzyme could participate in the acquisition of nutrients (Chang and Chang 1985, Mukkada 1985) and it could protect promastigotes from degradation by the midgut digestive enzymes. Sand fly midgut proteases appear to reach peak activities about one to three days after feeding (Borovsky and Schlein 1987, Dillon and Lane 1993, Mahmood and Borovsky 1993, Schlein and Jacobson 1998), which corresponds with decreased infections of L. amazonensis transfectants with blocked GP63 synthesis in Lutzomyia longipalpis (Hajmová et al. 2004). In contrast, Joshi et al. (2002) reported that L. major GP63-deficient mutants demonstrated normal development inside the sand fly vector Phlebotomus duboscqi.

LPG is composed of a GPI anchor, a conserved hexasaccharide core, a linear array of phosphorylated oligosaccharide repeat units and a saccharide cap (Turco and 
Descoteaux 1992). The interspecific polymorphism in LPG structure is expressed in the type and number of oligosaccharide side chains branching from the conserved backbone repeat units (Turco and Sacks 2003). These species-specific differences are involved in the regulation of the attachment and detachment of promastigotes in the sand fly gut (reviewed by Sacks and Kamhawi 2001). During metacyclogenesis, the development of infective metacyclic forms is accompanied by about two-fold elongation of the molecule and subtle compositional changes in termination of side chains of the units (Sacks et al. 1990). The resulting metacyclic promastigotes display markedly enhanced resistance to both complement-mediated lysis and macrophage killing-mechanisms (reviewed by Sacks 1992).

Besides of GP63 and LPG, many other factors influencing the life cycle of Leishmania have been reported; in the present study we have focused to the variation in a minichromosome production. The Leishmania genome comprises 36 chromosomes ranging from 0.35 to $\sim 3 \mathrm{Mb}$ in L. infantum and the linkage groups are conserved in L. major, L. tropica and L. aethiopica (Wincker et al. 1996). In some occasions, episomal circular or linear additional DNAs (also called minichromosomes) can be observed. Both forms arise by a gene amplification from a large source chromosome. They are often present in multiple copies and may arise (i) in strains selected for drug or after nutrient stress, or (ii) spontaneously in unselected stocks, as in the case of LD1/CD1 elements (Segovia and Ortiz 1997). Two genes from the LD1 region were identified: ORFG $(B T 1)$ encodes a biopterin transporter (Lemley et al. 1999) and $O R F F$ gene product is localised within the parasite nucleus (Ghosh et al. 1999).

Comparison of GP63 in strains/lines with different biology may contribute to the recognition of the significance of this molecule in the host and/or in the vector part of the Leishmania life cycle. Therefore, the study presented here was aimed at a characterisation of GP63 in four strains of L. major which differ in the virulence for mice (Sádlová et al. 1999), the ability to develop in the vector sand flies $P$. papatasi and $P$. duboscqi ( $\check{C}$ háková and Volf 1997) and the production of metacyclic LPG in stationary-phase promastigotes (Sádlová et al. 1999). Gene structure and dosage, protein amount and proteolytical activity of GP63 were ascertained. In addition, changes in these GP63 characters associated with serial passage of an avirulent parasite line through mice or sand flies were investigated. All the strains/lines were karyotyped and variation in minichromosome production was observed. The possible synergetic role of GP63, LPG and minichromosomes in the relationship of the parasite with the vector and the mammal host is discussed.

\section{MATERIALS AND METHODS}

Leishmania strains and culture. Four strains of Leishmania major Yakimoff et Schokhor were used: LV561 (LRCL137; MHOM/IL/1967/ Jericho-II), FV1 (MHOM/IL/1980/ Friedlin), Neal (MRHO/SU/1959/P), and L119 (MTAT/KE/ 195?/T4). The two Israeli strains (LV561, FV1) originate from human cutaneous lesions; the L119 and the Neal strains were isolated in Kenya from the gerbil Tatera nigricauda (Heisch et al. 1959) and in Uzbekistan from the gerbil Rhombomys opimus, respectively. Dr. Safyanova (Gamaleya Institute, Moscow) provided the low virulent line of Neal strain used for the present study. Four different lines of the strain LV561 were studied: the virulent line (LV561/V) was used after fresh reisolation from $\mathrm{BALB} / \mathrm{c}$ mice (less then 5 in vitro subcultures); the avirulent line (LV561/AV) was attenuated by more then 40 in vitro passages in culture, and the lines LV561/ AVM5 and LV561/AVS5 were obtained from the LV561/AV line by five subsequently passages through mice (AVM) and sand flies Phlebotomus duboscqi Neveu-Lemaire (AVS), respectively (Sádlová et al. 1999). All the strains and lines were tested previously for the infectivity and virulence in BALB/c mice (Sádlová et al. 1999). High virulence (rapid lesion development) was observed in LV561/V line, while delayed lesion development was found in both FV1 and L119 strains. The line of L119 reisolated from a mouse lesion is named L119/V. The Neal strain and LV561/AV, LV561/ AVM5 and LV561/AVS5 lines were avirulent (no lesions appeared throughout experiments lasting 6 or even 9 months). However, all lines retain the infectivity for mice, as the parasites were reisolated from inguinal nodes in some animals inoculated in the rump (Sádlová et al. 1999). In Neal strain, moreover, freshly reisolated parasites were able to cause lesions after re-inoculation into mice (Svobodová and Sádlová, unpublished observation). Parasites were maintained at $25^{\circ} \mathrm{C}$ on SNB-9 rabbit blood agar or RPMI 1640 medium (SIGMA) supplemented with $10 \%$ foetal calf serum and $45 \mu \mathrm{g}$ Gentamicin/ml, and subcultured at four-day intervals.

Molecular karyotyping. Agarose blocks containing chromosomal DNA were prepared as described by Van Der Ploeg et al. (1984) for trypanosomes. OFAGE using equipment described by Dujardin et al. (1987) were performed on $1.5 \%$ agarose gels in $0.4 \times \mathrm{TBE}$ running buffer at $7-12^{\circ} \mathrm{C}$ for 23 hours. Three distinct runs with 45-, 65-, and 125-s pulses achieved resolution of the whole karyotype. The karyotype of reference strain L. braziliensis M2903 (Dujardin et al. 1993a) was used to determine the sizes of chromosomal bands. Amount of minichromosomes amplified in some lines of LV561 strain was established densitometrically. Chromosomal bands resolved by OFAGE using 125-s pulses were transferred onto nylon membrane and hybridized according to manufacturer's instructions (Amersham). Three different hybridisation probes were used: pLb-134Sp (most conserved part of L. braziliensis gp63 gene; Dujardin et al. 1994), pLb-22 (putative serine/threonine protein kinase from $L$. braziliensis M2904; Dujardin et al. 1993b and unpublished data), and SSUcl79 (a highly conserved fragment of the 18S rDNA gene; 
Van Eys et al. 1992); the two latter probes are linked on chromosome 27 (Inga et al. 1998). Molecular karyotyping of strains was used also to check the identity of the different lines maintained in parallel.

DNA isolation and RFLP. Genomic DNA was isolated as described by Sambrook et al. (1989) and digested to completion with restriction enzymes (PstI, SalI, AluI and BglI) according to manufacturer's instructions (BRL). Electrophoresis was performed in a $10 \times 14 \mathrm{~cm}$ agarose $(0.7 \%)$ gel at $20 \mathrm{~V}$ overnight. Lambda HindIII DNA ladder (BRL) was used to estimate the size of DNA molecules.

Immunodetection of GP63. SDS-PAGE was performed according to Leammli (1970) on 10\% gel (thickness $0.75 \mathrm{~mm}$ ) under reduced conditions; stationary phase parasites $\left(10^{7}\right), 6$ day after subculture, were loaded per lane (equal numbers of promastigotes were preferred instead of equal amount of protein load). After separating the proteins, gels were stained with Coomassie Brilliant blue R-250 (Serva) or proteins were transferred to nitrocellulose membrane according to Towbin et al. (1979). The membrane was rinsed in TRIS-Tw buffer (20 $\mathrm{mM}$ TRIS, $150 \mathrm{mM} \mathrm{NaCl}, 0.1 \%$ TWEEN 20, pH 7.6), blocked overnight in 5\% fat-free milk, washed in TRIS-Tw and incubated for $1 \mathrm{~h}$ with rabbit anti-GP63 antiserum (1:100 dilution in $5 \%$ FCS). Polyclonal anti-GP63 antiserum obtained from rabbit injected with the bacterial lipoprotein / L. major GP63 fusion protein (Cornelis et al. 1996) was kindly provided by Prof. P. Cornelis (Vrije University of Brussels, Belgium). After washing in TRIS-Tw, the membrane was incubated for 45 min with peroxidase-conjugated swine anti-rabbit immunoglobulins (SEVAC, Prague) diluted 1:500 in TRIS-Tw and washed in TRIS-Tw. The peroxidase reaction product was developed in PBS buffer with 4-chloro-1-naphtol and 30\% $\mathrm{H}_{2} \mathrm{O}_{2}$. Densitometry was done using computer programme Digital Image Processing System (DIPS) version 5.0.

Protease activity of GP63 on gelatine gels. SDS-PAGE was carried out on $10 \%$ gels co-polymerised with $0.1 \%$ gelatine under non-reduced conditions. The same parasite samples as described for SDS-PAGE were loaded. Gels were soaked three times for 10 minutes in $0.5 \%$ Nonidet in TRIS-NaCl, incubated in TRIS- $\mathrm{NaCl}$ at $37^{\circ} \mathrm{C}$ overnight and then stained with Coomassie blue. Proteolytical activity was detected as a clear band on a blue-stained gelatine background. Densitometry was done as described previously.

Statistical analysis. All the statistical evaluations were made using the computer programme Statistica 6. Data were transformed to relative values and nonparametric Spearman test was used.

\section{RESULTS}

\section{Karyotype analysis and chromosome location of $g p 63$ genes}

Karyotypes of strains LV561, FV1, L119 and Neal were significantly different; differences between strains were apparent in the range of both the high as well as the low molecular weight chromosome-sized bands (Fig. 1a). Within strain LV561 (Fig. 2a, c), the four lines presented the same karyotype profile with the exception of one band corresponding to small linear DNA of about $200 \mathrm{~kb}$, which was not found in virulent
LV561/V line. This minichromosome emerged in attenuated LV561/ AV line. Further passaging of this line through sand flies (LV561/AVS5) led to the increase of minichromosome copies to about $110 \%$ while passaging through mice (LV561/AVM5) decreased the amount of amplicons to about $20 \%$ of the initial state (Fig. 2c). Statistically, amount of minichromosomes was negatively correlated with percentage of mice infections $(\mathrm{R}=$ $-0.9145 ; \mathrm{t}=-5.0552 ; \mathrm{P}=0.0039)$; the correlation with sand fly infections was positive, but insignificant $(\mathrm{R}=$ $0.4703, t=1.1915, P=0.2869)$. An unexpectedly high correlation with development in sand flies was found counting this factor together with production of metacyclic LPG in the strains: $\mathrm{R}=0.7853, \mathrm{t}=2.8368, \mathrm{P}=$ 0.0363 . On the other hand, in lines of L119 strain the karyotype was the same in promastigotes used for mice infection and those reisolated from the lesion (L119/V).

Hybridisation of gp63 probe to Southern blots from OFAGE showed that one chromosome-sized band of about $570 \mathrm{~kb}$ (chromosome 10) bears the gp63 genes in all the strains and lines (Figs. 1b, 2b). The hybridisation intensities of gp63 probe to chromosome 10 were not equal in all strains but the control, rehybridisation of the same OFAGE blots with probes cl79 and pLb-22, both linked to chromosome 27 (Inga et al. 1998), showed that the differences found among strains and lines should be attributed to the total quantity of loaded cells, not to gene dosage of gp63 (data not shown).

\section{Structure of the gp63 gene locus}

The structure of the gp63 locus was examined by hybridisation of $g p 63$ probe to genomic DNA cleaved with various restriction enzymes. Fig. 3 represents patterns obtained using SalI enzyme, which cuts within the intergenic region of the repeats (Button et al. 1989, Murray et al. 1990). All isolates showed identical restriction fragment lengths for the gp63 gene with a small exception in Neal strain (one band in SalI restriction pattern is smaller). This suggests conservation of gp63 genomic organisation among strains and lines here analysed.

Densitometrical scanning of Sall patterns confirmed a copy number of seven gp63 genes: a relative intensity 1 for each weakly hybridising band (two separated genes) and intensity 5 for the strongly hybridising band (cluster of five tandemly repeated genes).

\section{Expression and protease activity of GP63}

SDS-PAGE results revealed no significant differences (Fig. 4a, d) in protein patterns in the GP63 region among samples. Immunoblotting with polyclonal rabbit antiserum showed that expression of surface metalloproteinase GP63 differed among strains and lines (Figs. 4b, e). In comparison with the virulent line LV561/V (causing rapid lesion development in $100 \%$ of mice), expression of GP63 was reduced to one half in avirulent line LV561/AV (causing no lesions in mice). Similar differences were apparent using the GP63 protease activity 


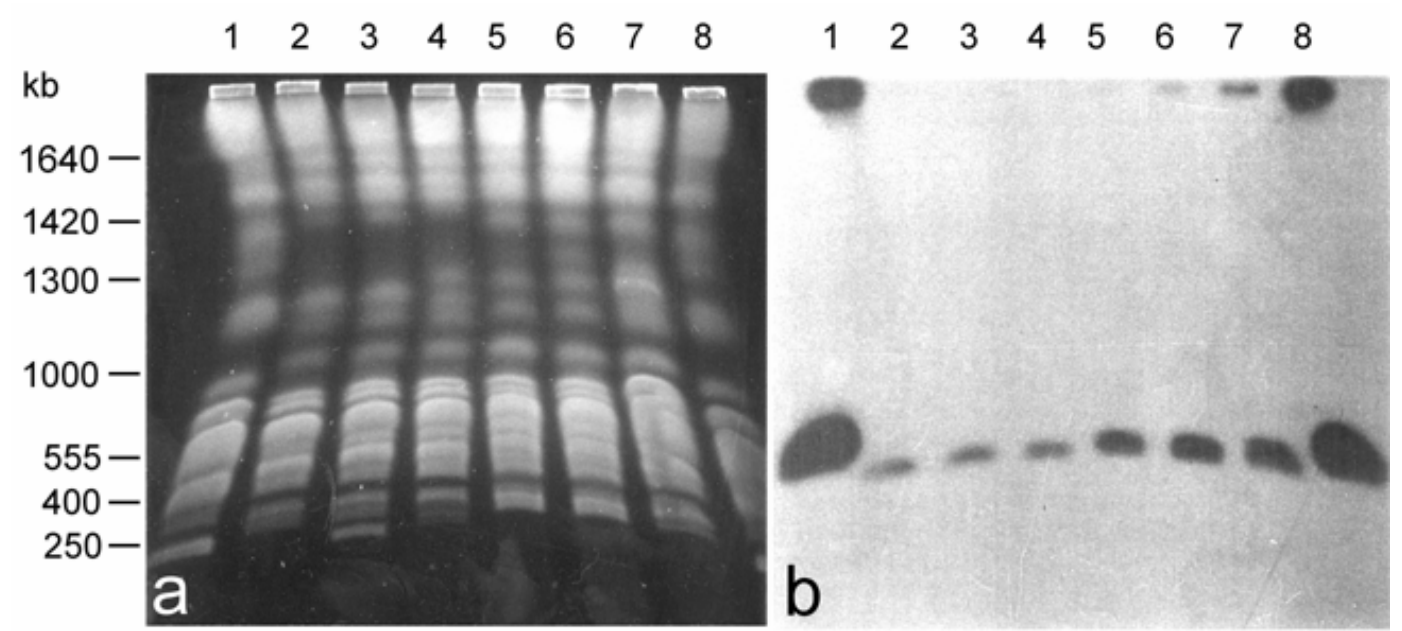

Fig. 1. Chromosomal location of gp63 genes in Leishmania major strains. a. Chromosome-sized bands resolved by OFAGE using 125-s pulses. b. Hybridisation with gp63 probe pLb-134Sp. Lanes: 2 - LV561/V; 3 - LV561/AV; 4 - FV1; 5 - L119; 6 L119/V; 7 - Neal; 1 and 8 - L. braziliensis M2903.

assay on gelatine gels (Fig. 4c, f, Table 1). The lines of the LV561 strain passaged through mice and sand flies (AVM5, AVS1, AVS2, and AVS5) expressed twice as much GP63 as compared with the original avirulent line LV561/AV (Fig. 4e). The increase of GP63 protein amount in passaged lines AVM5 and AVS5 was accompanied with an increase in protease activity to the level observed in LV561/V line (Fig. 4f). As shown previously (Sádlová et al. 1999), these passaged lines (AVM5, AVS5) remained avirulent for mice, but developed in sand flies significantly better than the original avirulent line (LV561/AV).

GP63 protein amount and enzymatic activity on gelatine gels were considerably elevated in both L119 and Neal strains (Figs. 4b, c) where decreased expression of metacyclic LPG and poor development in sand flies were previously observed (Čiháková and Volf 1997, Sádlová et al. 1999). Higher enzymatic activity in L119 and Neal strains was confirmed by the azocasein assay (Sádlová et al., unpubl.)

Statistical analysis (nonparametric Spearman test) confirmed that GP63 activity of strains/lines did not correlate significantly with a percentage of mice infections or a percentage of heavily infected sand flies. The same was true for production of metacyclic LPG in these strains/lines. However, interesting results were obtained by counting expression of GP63 and metacyclic LPG together. There was no correlation with development in sand flies but very significant correlation with a percentage of infected mice $(\mathrm{R}=0.9189, \mathrm{t}=$ 5.2106, $\mathrm{P}=0.003$ ).

\section{DISCUSSION}

A common event in Leishmania species is a gene amplification from large source chromosomes producing small circular or linear additional DNAs, also called minichromosomes. The best known is the LD1 family of amplicons. In L. major, additional DNAs were still observed only as linear elements, originally designated as the 715-class DNAs (Beverley and Coburn 1990). In L. major LV561, three linear minichromosomes homologous to LD1 were described: M180 (180-kb), M210 (210-kb) and M230 (230-kb) or M240 (240-kb) (Navarro et al. 1992, Ortiz and Segovia 1995, 1996). These minichromosomes showed striking plasticity with regard to size/number, when followed through multiple transfer during in vitro culture and in vivo passage in $\mathrm{BALB} / \mathrm{c}$ mice. All clones of LV561 containing these elements analysed by Navarro et al. (1992) were highly virulent. However, the authors suggested that these elements do not code any function essential for parasite virulence or indeed survival since clones containing LD1 amplified elements were not more virulent than those lacking them. The present results confirm this opinion, as the virulent line LV561/V did not have this minichromosome. The small linear DNA of about 200 $\mathrm{kb}$ emerged during attenuation of LV561 strain in culture (LV561/AV line). Parasites of this line passaged through sand flies (LV561/AVS5) showed further increase of minichromosome copies while passaging through mice (LV561/AVM5) had an opposite effect and amount of minichromosome copies was negatively correlated with percentage of mice infections in tested strains. Therefore, the amplification of LD1, which cause overexpression of BT1 and enhanced uptake of biopterin (Lemley et al. 1999, Dole et al. 2002), appears to be more advantageous in promastigotes cultured in vitro and/or for their development in the sand fly and is not essential for a successful vertebrate host infection.

High similarity was found in the structure and copy numbers of gp63 genes even among L. major strains/ lines with marked differences in amount and proteolytical activity of the GP63 protein. Therefore, phenotypic differences found originate probably on the level of posttranscriptional regulation of the gp63 gene product. 

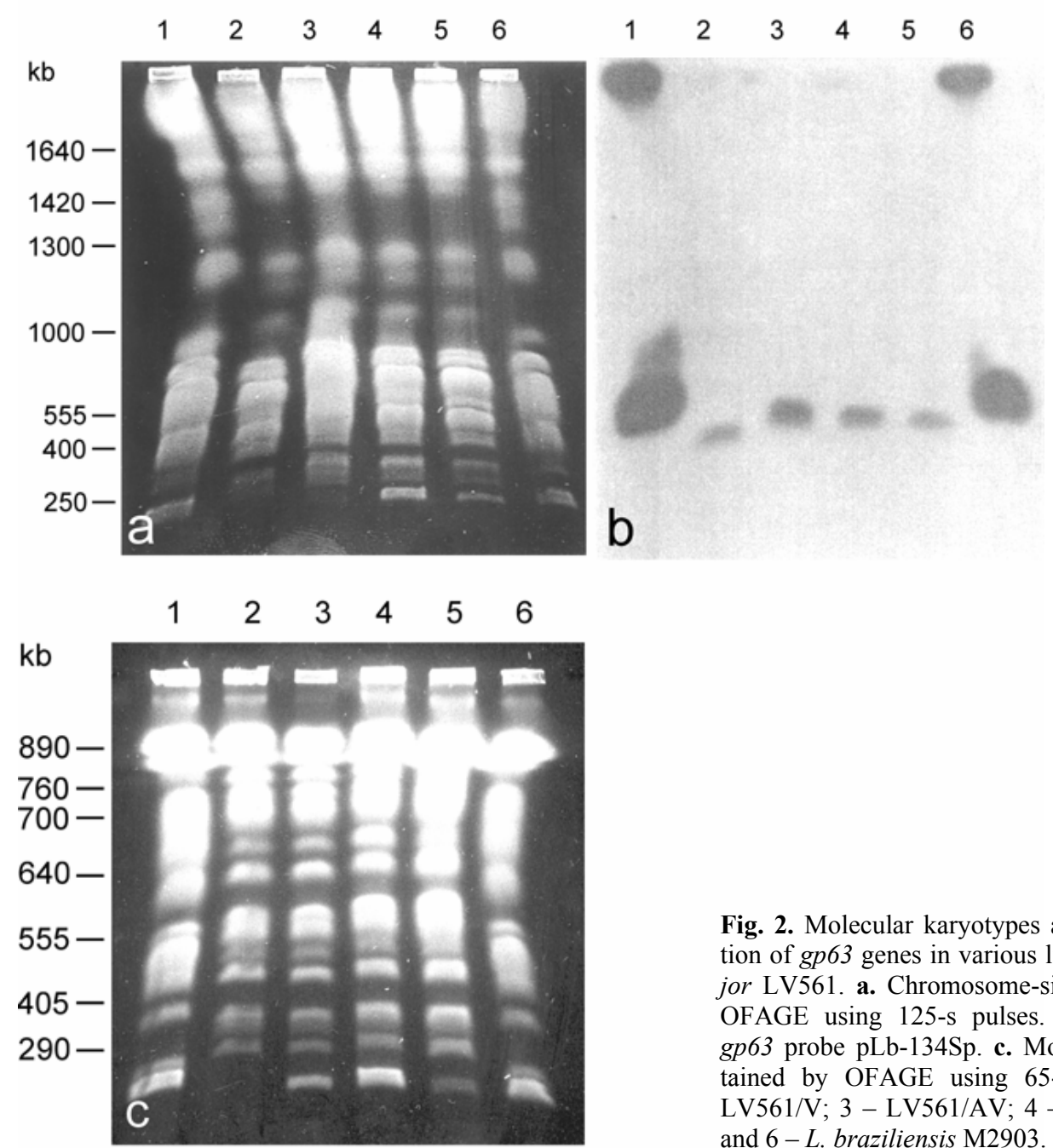

This finding is in accordance with results of other authors; Wilson et al. (1989) observed reduced amount of GP63 protein in attenuated $L$. chagasi parasites in comparison with the virulent line, but they did not find genomic changes in the gp63 locus. Similarly, in clones derived from L119 strain of L. major, Murray et al. (1990) described widely fluctuating GP63 protein levels without apparent changes in the gp63 gene locus. This does not exclude the possibility that in some cases, genomic changes could affect gp63 gene expression; in Neotropical Leishmania species, the lower pathogenicity of $L$. peruviana was correlated with a strong reduction in copy number of gp63 genes and the absence of a specific gene family (Victoir et al. 1998).

The protein amount and enzymatic activity of GP63 in L. major strains and lines described in this study is interpreted with knowledge of their biological differences, i.e., infectivity and virulence for BALB/c mice and development in sand flies (Čiháková and Volf 1997, Sádlová et al. 1999) and expression of metacyclic LPG in promastigotes (Sádlová et al. 1999). These data are summarised in Table 1. Both expression and proteolytical activity of GP63 were very low in avirulent line

Fig. 2. Molecular karyotypes and chromosomal location of gp63 genes in various lines of Leishmania major LV561. a. Chromosome-sized bands resolved by OFAGE using 125-s pulses. b. Hybridisation with gp63 probe pLb-134Sp. c. Molecular karyotypes obtained by OFAGE using 65 -s pulses. Lanes: 2 LV561/V; 3 - LV561/AV; 4 - AVS5; 5 - AVM5; 1 and $6-$ L. braziliensis M2903.

LV561/AV. Reduced GP63 level is a frequent phenomenon in Leishmania promastigotes which underwent a long-termed maintenance in vitro. It was found in attenuated variants compared to virulent parasites in L. mexicana, L. chagasi, L. infantum and L. amazonensis (Chaudhuri and Chang 1988, Wilson et al. 1989, Santos-Gomes and Abranches 1996, Seay et al. 1996). An interesting point is that passaging through both mice and sand flies (AVS5 and AVM5 lines) led to an increase in the amount of GP63 and its enzymatic activity. It has been shown also by Roberts et al. (1995) that passage of attenuated parasites through mice stimulated to re-express surface $59 \mathrm{kDa}$ glycoprotein.

The data reported by Joshi et al. (1998, 2002) suggest that GP63 is not essential for the Leishmania development in sand flies. Their GP63 deficient mutants of $L$. major grow well in Phlebotomus argentipes and $P$. duboscqi, two sand fly species known for high susceptibility to various Leishmania species. In another parasitevector combination (L. amazonensis - Lutzomyia longipalpis), however, the GP63 appear to play a role in early stage of the infection: on day 2 post infective blood meal the GP63 deficient transfectants gave lower infec- 


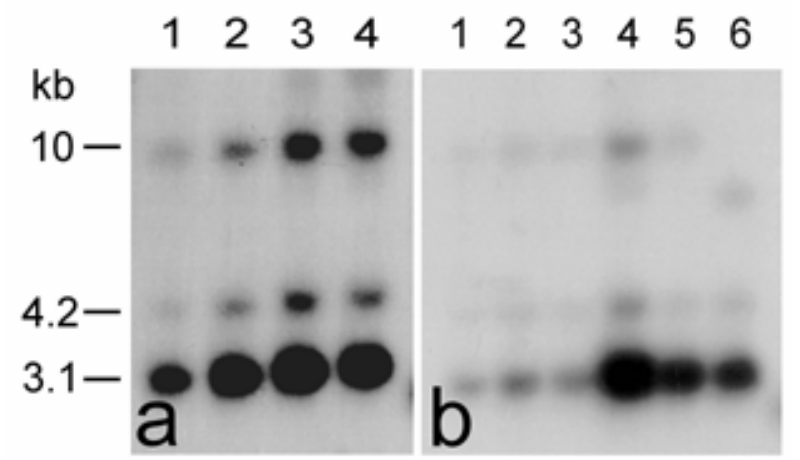

Fig. 3. Hybridisation of gp63 probe pLb-134Sp to genomic DNA cleaved with the restriction enzyme SalI. a. Various lines of the strain LV561 of Leishmania major: 1 - LV561/V; 2 - LV561/AV; 3 - AVS5; 4 - AVM5. b. Various strains of Leishmania major: 1 - LV561/V; 2 - LV561/AV; 3 - FV1; 4 - L119; 5 - L119/V; 6 - Neal.

tion rates and lower intensities of infection (Hajmová et al. 2004). In the present study, both passaged lines AVM5 and AVS5 with higher GP63 activity showed significantly better development in $P$. papatasi than initial LV561/AV (Table 1), but it cannot be excluded that some other molecules differ between these lines that might account for the correlation observed. In addition, the avirulent LV561/AV parasites with decreased amount of GP63 were able to develop heavy infections in up to $10 \%$ of flies with colonisation of the stomodeal valve. Two interpretations are possible: low amount of GP63 might be sufficient for development in sand flies or the sand fly midgut acts as a bottle neck selecting individuals with a higher amount of GP63.

High amount and proteolytical activity of GP63 in L119 and Neal strains did not compensate their poor grow in sand flies. The proportion of flies infected with both L119 and Neal strains in our previous experiments (Čiháková and Volf 1997) fall dramatically between days 3 and 6 post infective meal, which is the time of defecation of blood meal residues, when promastigotes have to escape from the peritrophic matrix and attach to the midgut. As the attachment of L. major in P. papatasi is mediated by lipophosphoglycan (LPG) (Sacks 2001), the main grow barrier is probably the defect in LPG reported for L119 strain by McConville and Homans (1992). Indeed, addition of the virulent LV561 glycoconjugates to L119 promastigotes raised the rate of infections in P. papatasi (Schlein et al. 1990) With respect to results of Hajmová et al. (2004) we may conclude that GP63 can protect promastigotes at the early stage of development in sand flies, but cannot compensate LPG defect at a subsequent developmental stage.

A role of GP63 in the host is indicated by the fact that parasites of L119 strain possessing LPG defect but very high GP63 activity caused lesion in $100 \%$ of inoculated mice (Table 1). However, the GP63 enzymatic activity did not correlate simply with virulence/aviru- lence of $L$. major lines studied by our group (Table 1 ). This agrees with hypothesis that GP63 is only one of the invasive/evasive molecular determinants of Leishmania parasites, the second very important one being LPG (Chang and McGwire 2002, Yao et al. 2003).

The overexpression of the metalloproteinase GP63 in both strains defective in production of metacyclic LPG (L119, Neal) is the intriguing finding of this study. Previously, Murray et al. (1990) also observed higher level of GP63 expression in L119 strain, comparing to virulent LV561 strain, and suggested that this phenomenon may be associated with lack of detectable levels of LPG in this strain. Both GP63 and LPG are surface molecules anchored by GPI; they both contribute to a phenotype and are probably crucial for the parasite survival in the vertebrate host (see also Sádlová 1999). Compensation of one molecule by the second (by mechanisms yet unknown) might be a contra-strategy of the parasite on how to avoid a lethal defect. Our results support this hypothesis: summarised data of GP63 activity and metacyclic LPG production in different strains/lines of $L$. major gave very significant correlation with their success in mice infections. Calculating separately, there was no correlation.

Recent genetic studies with well-defined mutants allow exact evaluation of the respective virulence factors. The requirement of GP63 for parasite interaction with macrophages was confirmed in L. amazonensis (Chen et al. 2000) but was not found in L. major (Joshi et al. 1998) and L. mexicana (Hilley et al. 2000). Different results were obtained also with LPG mutants lacking the gene LPG1. While Ilg (2000) demonstrated that mutant $L$. mexicana clones did not require LPG for experimental infections of macrophages or mice, Späth et al. (2000) confirmed LPG as a virulence factor in L. major.

These results probably reflect surprising speciesspecific differences in the role of GP63 and LPG (reviewed by Turco et al. 2001) in the mammalian host. Therefore, some variability and plasticity in the relative importance of these two molecular determinants may be expected also in an intraspecific level. Chakrabarty et al. (1996) showed in two virulent strains of $L$. donovani that the contributory roles of GP63 and LPG differ either in recognition or in the rate of internalisation into macrophages. In their experiments, preblocking of macrophage receptors with either GP63 or LPG affect the entry of the one or the second virulent strain, respectively.

The substitution of these two molecules can be envisaged with respect to their suggested roles in the vertebrate host. Both LPG and GP63 have been implicated in crucial steps of Leishmania-host interactions, i.e., influence of monocyte migration (Frankenburg et al. 1990, 1992, Sörensen et al. 1994), attachment to macrophages (Russell 1987, Russell and Wright 1988, Da Silva et al. 1989, Talamas-Rohana et al. 1990), avoiding complement attack (Puentes et al. 1990, Brittingham et 

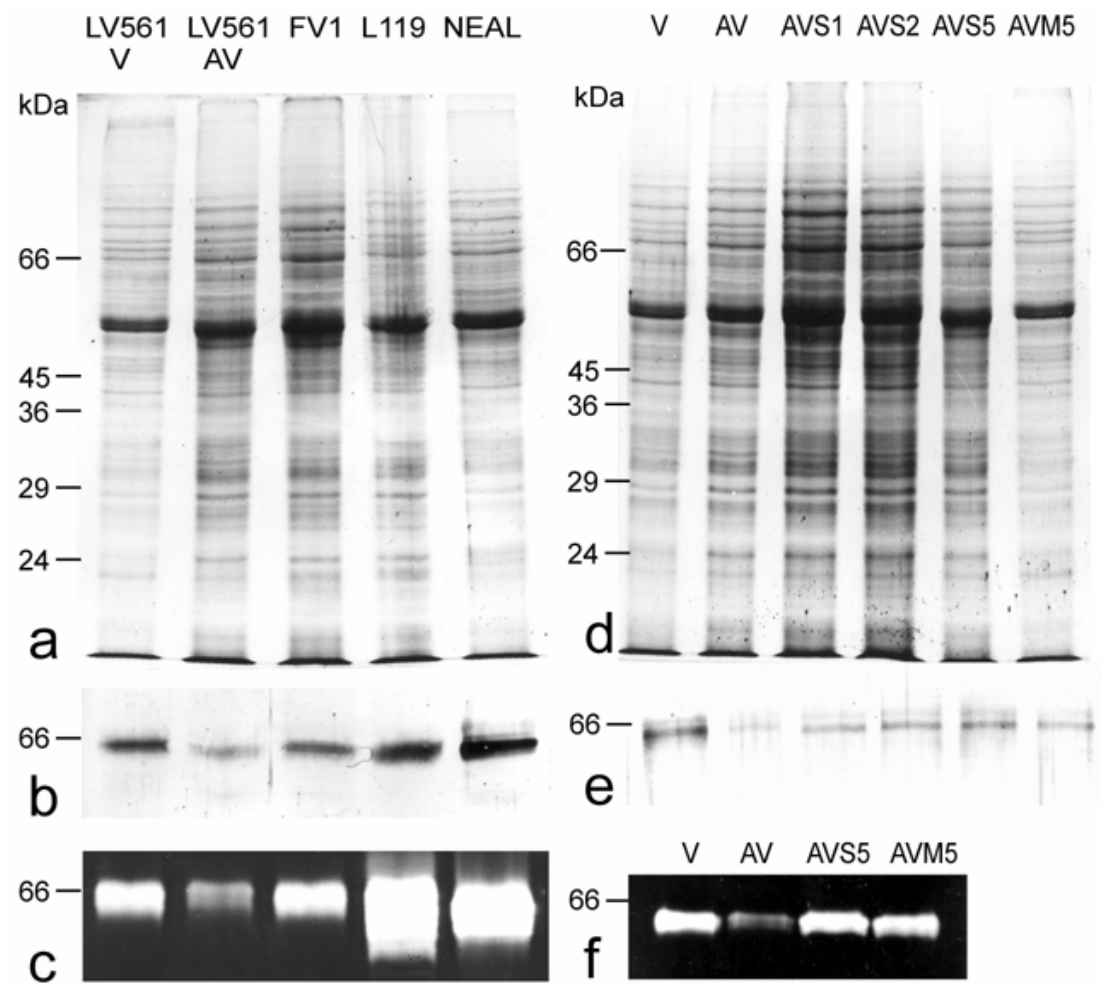

Fig. 4. Comparison of amount and enzymatic activity of GP63 in various Leishmania major strains (a, b, c) and various lines of Leishmania major LV561 (d, e, f). a, d. SDS-PAGE stained with Coomassie blue. b, e. Immunoblot with antibodies against GP63. c, f. Protease activity of GP63 on gelatine gels. Sigma markers were used.

Table 1. Correlation of enzymatic activity of GP63 with characters of the Leishmania major strains and lines described previously by Čiháková and Volf (1997)* and Sádlová et al. (1999).**

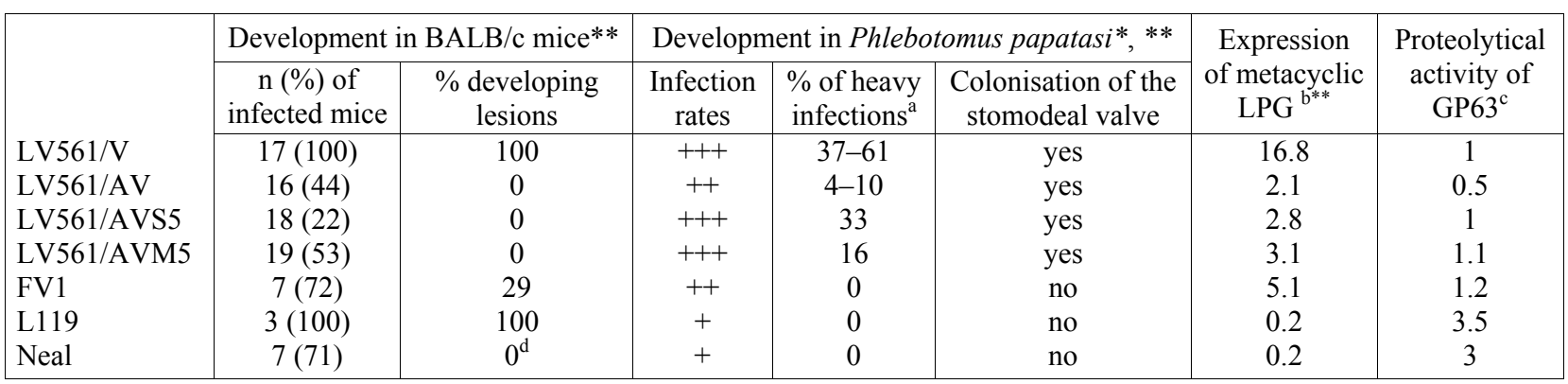

${ }^{\mathrm{a}}$ more than 500 parasites per gut; ${ }^{\mathrm{b}}$ proportion of stationary-phase promastigotes reacting with the monoclonal antibody $3 \mathrm{~F} 12$;

${ }^{c}$ results of densitometry; ${ }^{\mathrm{d}}$ re-inoculated parasites were able to cause lesions.

al. 1995, Joshi et al. 1998, 2002) and protection from degradation in macrophage phagolysosomes (McNeely and Turco 1990, Proudfoot et al. 1996, Seay et al. 1996, Späth et al. 2000). Some of the functions remain yet to be confirmed using gene knockout methods and some may be species-specific, but it is clear that these molecules accomplish in a different manner very similar functions.

However, our results with L119 and Neal strains indicated that the compensation of LPG defect by overexpression of GP63 is useless during the vector part of the life cycle. In sand fly these Leishmania molecules seem to fulfil quite different functions, and therefore, defect in LPG is lethal for the parasite. On the other hand, the products of LD1 amplicons seem to help Leishmania parasites in their development in the vector.

Acknowledgements. We thank Prof. P. Cornelis (Vrije University of Brussels) for providing anti-GP63 antibodies, Dr. M. Svobodová and Mrs. S. De Doncker for help during experiments. The research was supported by project MSM 0021620828 and by a grant of the Fund for Scientific Research-Flanders (KV.E 192/1997). J.S. and J.V. were supported by TEMPUS mobility grant S-JEP-07281/94. 


\section{REFERENCES}

BEVERLEY S.M., COBURN C.M. 1990: Recurrent de novo appearance of small linear DNAs in Leishmania major and relationship to extra-chromosomal DNAs in other species. Mol. Biochem. Parasitol. 42: 133-142.

BOROVSKY D., SCHLEIN Y. 1987: Trypsin and chymotrypsin-like enzymes of the sandfly Phlebotomus papatasi infected with Leishmania and their possible role in vector competence. Med. Vet. Entomol. 1: 235-242.

BOUVIER J., BORDIER C., VOGEL H., REICHELT R., ETGES R. 1989: Characterization of the promastigote surface protease of Leishmania as a membrane-bound zinc endopeptidase. Mol. Biochem. Parasitol. 37: 235-246.

BRITTINGHAM A., MORRISON C.J., McMASTER W.R., McGWIRE B.S., CHANG K.P., MOSSER D.M. 1995: Role of the Leishmania surface protease GP63 in complement fixation, cell adhesion, and resistance to complement-mediated lysis. J. Immunol. 155: 3102-3111.

BUTTON L.L., RUSSELL D.G., KLEIN H.L., MEDINAACOSTA E., KARESS R.E., McMASTER W.R. 1989: Genes encoding the major surface glycoprotein in Leishmania are tandemly linked at a single chromosomal locus and are constitutively transcribed. Mol. Biochem. Parasitol. 32: 271-284.

CHANG C.S., CHANG K.P. 1985: Heme requirement and acquisition by extracellular and intracellular stages of Leishmania mexicana amazonensis. Mol. Biochem. Parasitol. 16: 267-276.

CHANG K.P., McGWIRE B.S. 2002: Molecular determinants and regulation of Leishmania virulence. Kinetopl. Biol. Dis. 1(1).

CHAKRABARTY R., MUKHERJEE S., LU H.G., McGWIRE B.S., CHANG K.P., BASU M.K. 1996: Kinetics of entry of virulent and avirulent strains of Leishmania donovani into macrophages: a possible role of virulence molecules (GP63 and LPG). J. Parasitol. 84: 632635.

CHAUDHURI G., CHANG K.P. 1988: Acid protease activity of a major surface membrane glycoprotein (GP63) from Leishmania mexicana promastigotes. Mol. Biochem. Parasitol. 27: 43-52.

CHEN D.Q., KOLLI B.K., YADAVA N., LU H.G., GILMAN-SACHS A., PETERSON D.A., CHANG K.P. 2000: Episomal expression of specific sense and antisense mRNAs in Leishmania amazonensis: modulation of GP63 level in promastigotes and their infection of macrophages in vitro. Inf. Immun. 68: 80-86.

ČIHÁKOVÁ J., VOLF P. 1997: Development of different Leishmania major strains in the vector sandflies Phlebotomus papatasi and P. duboscqi. Ann. Trop. Med. Parasitol. 91: 267-279.

CORNELIS P., SIERRA J.C., LIM J.A., MALUR A., TUNGPRADABKUL S., TAZKA H., LEITAO A., MARTINS C.V., DI PERNA C., BRYS L., DE BEATSELIER P., HAMERS R. 1996: Development of new cloning vectors for the production of immunogenic outer membrane fusion proteins in Escherichia coli. Biotechnology 14: 203-208.

DA SILVA R.P., HALL B.F., JOINER K.A., SACKS D.L. 1989: CR1, the C3b receptor, mediates binding of infec- tive Leishmania major metacyclic promastigotes to human macrophages. J. Immunol. 143: 617-622.

DILLON R.J., LANE R.P. 1993: Bloodmeal digestion in the midgut of Phlebotomus papatasi and Phlebotomus langeroni. Med. Vet. Entomol. 7: 225-232.

DOLE V.S., MYLER P.J., STUART K.D., MANDHUBALA R. 2002: Expression of biopterin transporter protein (BT1) in Leishmania. FEMS Microbiol. Lett. 208: 89-91.

DUJARDIN J.C., DE DONCKER S., VICTOIR K., LE RAY D., HAMERS R., AREVALO J. 1994: Size polymorphism of chromosomes bearing gp63-genes in L. braziliensis and L. peruviana. Ann. Trop. Med. Parasitol. 88: 445-448.

DUJARDIN J.C., GAJENDRAN N., AREVALO J., LLANOS-CUENTAS A., GUERRA H., GOMEZ J., ARROYO J., DE DONCKER S., JACQUET D., HAMERS R., LE RAY D. 1993b: Karyotype polymorphism and conserved characters in the Leishmania (Viannia) braziliensis complex explored with chromosome-derived probes. Ann. Soc. Belge Med. Trop. 73: 101-118.

DUJARDIN J.C., GAJENDRAN N., HAMERS R., MATTHIJSEN G., URJEL R., RECACOECHEA M., VILLAROEL G., BERMUDEZ H., DESJEUX P., DE DONCKER S., LE RAY D. 1987: Leishmaniasis in the lowlands of Bolivia. VIII. Characterization and identification of Bolivian isolates by PFG karyotyping. In: D. Hart (Ed.), Leishmaniasis: the First Centenary (1885-1985). New Strategies for Control. NATO ASI Series A, Plenum Press, New York, pp. 137-148.

DUJARDIN J.C., LLANOS-CUENTAS A., CACERES A., ARANA M., DUJARDIN J.P., GUERRINI F., GOMEZ J., ARROYO J., DE DONCKER S., JACQUET D., HAMERS R., GUERRA H., LE RAY D., AREVALO J. 1993a: Molecular karyotype variation of Leishmania ( $\mathrm{V}$ annia) peruviana evidences geographical populations in Peru along a North-South cline. Ann. Trop. Med. Parasitol. 87 : $335-347$.

ETGES R. 1992: Identification of a surface metalloproteinase on 13 species of Leishmania isolated from humans, Crithidia fasciculata, and Herpetomonas samuelpessoai. Acta Trop. 50: 205-217.

ETGES R., BOUVIER J., BORDIER C. 1986: The major surface protein of Leishmania promastigotes is a protease. J. Biol. Chem. 261: 9098-9101.

FRANKENBURG S., GROSS A., LEIBOVICI V. 1992: Leishmania major and Leishmania donovani: effect of LPG-containing and LPG-deficient strains on monocyte chemotaxis and chemiluminescence. Exp. Parasitol. 75: 442-448.

FRANKENBURG S., LEIBOVICI V., MANSBACH N., TURCO S.J., ROSEN G. 1990: Effect of glycolipids of Leishmania parasites on human monocyte activity. J. Immunol. 145: 4284-4289.

GHOSH A., MADHUBALA R., MYLER P.J., STUART K.D. 1999: Leishmania donovani: characterization and expression of $O R F F$, a gene amplified from the LD1 locus. Exp. Parasitol. 93: 225-230.

HAJMOVÁ M., CHANG K.P., KOLLI B., VOLF P. 2004: Down-regulation of GP63 in Leishmania amazonensis re- 
duces its early development in Lutzomyia longipalpis. Microbes Infect. 6: 646-649.

HEISCH R.B., GRAINGER W.E., HARVEY A.E.C. 1959: The isolation of a Leishmania from gerbils in Kenya. J. Trop. Med. Hyg. 62: 158-159.

HILLEY J.D., ZAWADZKI J.L., McCONVILLE M.J., COOMBS G.H., MOTTRAM J.C. 2000: Leishmania mexicana mutants lacking glycosylphosphatidylinositol (GPI): protein transamidase provide insights into the biosynthesis and functions of GPI-anchored proteins. Mol. Biol. Cell 11: 1183-1195.

ILG T. 2000: Lipophosphoglycan is not required for infection of macrophages or mice by Leishmania mexicana. EMBO J. 19: 1953-1962.

INGA R., DE DONCKER S., GOMEZ J., LOPEZ M., GARCIA R., LE RAY D., AREVALO J., DUJARDIN J.C. 1998: Relation between variation in copy number of ribosomal RNA encoding genes and size of harbouring chromosomes in Leishmania of subgenus Viannia. Mol. Biochem. Parasitol. 92: 219-228.

JOSHI P.B., KELLY B.L., KAMHAWI S., SACKS D.L., McMASTER W.R. 2002: Targeted gene deletion in Leishmania major identifies leishmanolysin (GP63) as a virulence factor. Mol. Biochem. Parasitol. 120: 33-40.

JOSHI P.B., SACKS D.L., MODI G., McMASTER W.R. 1998: Targeted gene deletion of Leishmania major genes encoding developmental stage-specific leishmanolysin (GP63). Mol. Microbiol. 27: 519-530.

LAEMMLI U.K. 1970: Cleavage of structural proteins during the assembly of the head of bacteriophage T4. Nature 227: 680-685.

LEMLEY C., YAN S., DOLE V.S., MADHUBALA R., CUNNINGHAM M.L., BEVERLEY S.M., MYLER P.J., STUART K.D. 1999: The Leishmania donovani LD1 locus gene $O R F G$ encodes a biopterin transporter (BT1). Mol. Biochem. Parasitol. 104: 93-105.

MAHMOOD F., BOROVSKY D. 1993: Biosynthesis of serine proteases in Lutzomyia anthophora (Diptera: Psychodidae). J. Med. Entomol. 30: 683-688.

McCONVILLE M.J., HOMANS S.W. 1992: Identification of the defect in lipophosphoglycan biosynthesis in a nonpathogenic strain of Leishmania major. J. Biol. Chem. 267: 5855-5861.

McNEELY T.B., TURCO S.J. 1990: Requirement of lipophosphoglycan for intracellular survival of Leishmania donovani within human monocytes. J. Immunol. 144: 2745-2750.

MEDINA-ACOSTA E., BEVERLEY S.M., RUSSELL D.G. 1993: Evolution and expression of the Leishmania surface proteinase (gp63) gene locus. Infect. Agents Dis. 2: 25-34.

MUKKADA A.J. 1985: Energy metabolism in Leishmania. In: K.P. Chang and R.S. Bray (Eds.), Human Parasitic Diseases. Vol. 1. Leishmaniasis. Elsevier, Amsterdam, pp. 49-64.

MURRAY P.J., HANDMAN E., GLASER T.A., SPITHILL T.W. 1990: Leishmania major: expression and gene structure of the glycoprotein 63 molecule in virulent and avirulent clones and strains. Exp. Parasitol. 71: 294-304.

NAVARRO M., MAINGON R., HAMERS R., SEGOVIA M. 1992: Dynamics and size polymorphism of minichromo- somes in Leishmania major LV-561 cloned lines. Mol. Biochem. Parasitol. 55: 65-74.

ORTIZ G., SEGOVIA M. 1995: Location in the source chromosome of the 180-kb minichromosome of Leishmania major and characterization of the novel junction. Mol. Biochem. Parasitol. 71: 153-161.

ORTIZ G., SEGOVIA M. 1996: Characterisation of the novel junction of two minichromosomes of Leishmania major. Mol. Biochem. Parasitol. 82: 137-144.

PROUDFOOT L., NIKOLAEV A.V., FENG G.J., WEI X.Q., FERGUSON M.A.J., BRIMACOMBE J.S., LIEW F.Y. 1996: Regulation of the expression of nitric oxide synthase and leishmanicidal activity by glycoconjugates of Leishmania lipophosphoglycan in murine macrophages. Proc. Natl. Acad. Sci. USA 93: 10984-10989.

PUENTES S.M., DA SILVA R.P., SACKS D.L., HAMMER C.H., JOINER K.A. 1990: Serum resistance of metacyclic stage Leishmania major promastigotes is due to release of C5b-9. J. Immunol. 145: 4311-4316.

ROBERTS S.C., WILSON M.E., DONELSON J.E. 1995: Developmentally-regulated expression of a novel 59-kDa product of the major surface protease (Msp or gp63) gene family of Leishmania chagasi. J. Biol. Chem. 270: 8884 8892.

RUSSELL D.G. 1987: The macrophage-attachment glycoprotein GP63 is the predominant C3-acceptor site on Leishmania mexicana promastigotes. Eur. J. Biochem. 104: 213-221.

RUSSELL D.G., WRIGHT S.D. 1988: Complement receptor type 3 (CR3) binds to an Arg-Gly-Asp-containing region of the major surface glycoprotein, GP63, of Leishmania promastigotes. J. Exp. Med. 168: 279-292.

SACKS D.L. 1992: The structure and function of the surface lipophosphoglycan in different developmental stages of Leishmania promastigotes. Infect. Agents Dis. 1: 200-206.

SACKS D.L. 2001: Leishmania-sand fly interactions controlling species-specific vector competence. Cell. Microbiol. 3: 189-196.

SACKS D.L., BRODIN T.N., TURCO S.J. 1990: Developmental modification of the lipophosphoglycan from Leishmania major promastigotes during metacyclogenesis. Mol. Biochem. Parasitol. 42: 225-234.

SACKS D.L., KAMHAWI S. 2001: Molecular aspects of parasite-vector and vector-host interactions in leishmaniasis. Annu. Rev. Microbiol. 55: 453-483.

SÁDLOVÁ J. 1999: The life history of Leishmania (Kinetoplastida: Trypanosomatidae). Acta Soc. Zool. Bohem. 63: 331-366.

SÁDLOVÁ J., SVOBODOVÁ M., VOLF P. 1999: Leishmania major: effect of repeated passages through sand fly vectors or murine hosts. Ann. Trop. Med. Parasitol. 93: 599-611.

SAMBROOK J., FRITSCH E.F., MANIATIS T. 1989: Molecular cloning. $2^{\text {nd }}$ Edn. Cold Spring Harbor Laboratory Press, New York.

SANTOS-GOMES G.M., ABRANCHES P. 1996: Comparative study of infectivity caused by promastigotes of Leishmania infantum MON-1, L. infantum MON-24 and L. donovani MON-18. Folia Parasitol. 43: 7-12. 
SCHLEIN Y., JACOBSON R.L. 1998: Resistance of Phlebotomus papatasi to infection with Leishmania donovani is modulated by components of the infective bloodmeal. Parasitology 117: 467-473.

SCHLEIN Y., SCHNUR L.F., JACOBSON R.L. 1990: Released glycoconjugate of indigenous Leishmania major enhances survival of a foreign L. major in Phlebotomus papatasi. Trans. R. Soc. Trop. Med. Hyg. 84: 353-355.

SEAY M.B., HEARD P.L., CHAUDHURI G. 1996: Surface $\mathrm{Zn}$-proteinase as a molecule for defence of Leishmania mexicana amazonensis promastigotes against cytolysis inside macrophage phagolysosomes. Infect. Immun. 64: 5129-5137.

SEGOVIA M., ORTIZ G. 1997: LD1 amplification in Leishmania. Parasitol. Today 13: 342-348.

SÖRENSEN A.L., HEY A.S., KHARAZMI A. 1994: Leishmania major surface protease GP63 interferes with the function of human monocytes and neutrophils in vitro. APMIS 102: 265-271.

SPÄTH G.F., EPSTEIN L., LEADER B., SINGER S.M., AVILA H.A., TURCO S.J., BEVERLEY S.M. 2000: Lipophosphoglycan is a virulence factor distinct from related glycoconjugates in the protozoan parasite Leishmania major. Proc. Natl. Acad. Sci. USA 97: 9258-9263.

TALAMAS-ROHANA P., WRIGHT S.D., LENNARTZ M.R., RUSSELL D.G. 1990: Lipophosphoglycan from Leishmania mexicana promastigotes binds to members of the CR3, p150, 95 and LFA-1 family of leukocyte integrins. J. Immunol. 144: 4817-4824.

TOWBIN H., STEAHLIN T., GORDON J. 1979: Electrophoretic transfer of proteins from polyacrylamide gels to nitrocellulose sheets: procedure and some applications. Proc. Natl. Acad. Sci. USA 76: 4350-4354.

TURCO S.J., DESCOTEAUX A. 1992: The lipophosphoglycan of Leishmania parasites. Annu. Rev. Microbiol. 46: $65-94$.

TURCO S.J., SACKS D.L. 2003: Control of Leishmania-sand fly interactions by polymorphism in lipophosphoglycan structure. Methods Enzymol. 363: 377-381.
TURCO S.J., SPÄTH G.F., BEVERLEY S.M. 2001: Is lipophosphoglycan a virulence factor? A surprising diversity between Leishmania species. Trends Parasitol. 17: 223226.

VAN DER PLOEG L.H.T., CORNELISSEN W.C.A, MICHELS P.A.M., BORST P. 1984: Chromosome rearrangements in Trypanosoma brucei. Cell 39: 213-221.

VAN EYS G.J.M., SCHOONE G.J., KROON N.C.M., EBELING S.B. 1992: Sequence analysis of small subunit ribosomal RNA genes and its use for detection and identification of Leishmania parasites. Mol. Biochem. Parasitol. 51: 133-142.

VICTOIR K., BAÑULS A.L., AREVALO J., LLANOSCUENTAS A., HAMERS R., NOEL S., DE DONCKER S., LE RAY D. 1998: The gp63 gene locus, a target for genetic characterisation of Leishmania belonging to subgenus Viannia. Parasitology 117: 1-13.

VOTH B.R., KELLY B.L., JOSHI P.B., IVENS A.C., McMASTER W.R. 1998: Differentially expressed Leishmania major gp63 genes encode cell surface leishmanolysin with distinct signals for glycosylphosphatidylinositol attachments. Mol. Biochem. Parasitol. 93: 31-41.

WINCKER P., RAVEL CH., BLAINEAU C., PAGES M., JAUFFRET Y., DEDET J.-P., BASTIEN P. 1996: The Leishmania genome comprises 36 chromosomes conserved across widely divergent human pathogenic species. Nucleic Acids Res. 24: 1688-1694.

WILSON M.E., HARDIN K.K., DONELSON J.E. 1989: Expression of the major surface glycoprotein of Leishmania donovani chagasi in virulent and attenuated promastigotes. J. Immunol. 143: 678-684.

YAO C.Q., DONELSON J.E., WILSON M.E. 2003: The major surface protease (MSP or GP63) of Leishmania sp. - Biosynthesis, regulation of expression, and function. Mol. Biochem. Parasitol. 132: 1-16.

Accepted 17 October 2005 